\title{
Uma experiência com alunos e professores de nível médio avaliando objetos de aprendizagem
}

\author{
Valéria Machado da Costa \\ Clevi E. Rapkiewicz \\ Maria Cristina Canela \\ Gláucia Ribeiro Gonzaga \\ \{costavm; clevirap; mccanela; glauciargonzaga\}@gmail.com
}

Resumo: Com a popularização da Internet, a quantidade de material digital disponível para ser utilizada aumenta cada vez mais, inclusive na educação. Muitas vezes, porém, os usuários não têm parâmetros para saber se a fonte que estão consultando é de qualidade ou não. Uma das formas de optar por um material é o mesmo já ter sido avaliado por um par, isto é, alguém do mesmo nível ou da mesma área. Este artigo relata o desafio de inserir alunos de nível médio no contexto do processo de avaliação de objetos de aprendizagem. Após a avaliação de 55 objetos nas áreas de Química, Física, Matemática e Biologia disponíveis no repositório do RIVED, verificou-se, por um lado, a pertinência de alunos avaliarem material que eles próprios irão utilizar, e, por outro, a influência do nível de inclusão digital dos alunos no processo de avaliação.

Palavras-chave: inclusão digital; avaliação; objetos de aprendizagem;

\section{Introdução}

É sabido que o desenvolvimento de qualquer produto, seja ele computacional ou não, deve ter como foco seu usuário final. No caso de produtos digitais, principalmente educacionais, é importante que este usuário participe das etapas de desenvolvimento e/ou que no final valide esse produto por meio de algum tipo de avaliação.

Segundo Almeida:

Atualmente, o cidadão comum e anônimo tem cada vez mais informação mas paradoxalmente menor conhecimento, por isso saber produzir e saber gerir informação, não só é um desafio permanente, como também um autêntico imperativo categórico que impõe novas formas de abordagem e renovado capital intelectual, ou melhor, pessoas, cada vez mais bem preparadas face às diferentes realidades. (ALMEIDA, 2007, p. 46).

É preciso educar o cidadão para que este se torne crítico e consciente, capaz de pesquisar, utilizar e produzir informação, passando de mero receptor a também emissor (EMIREC) ou, em outras palavras, tornando-se um prosumidor - um produtor e consumidor de conteúdo.

O primeiro passo para formar esse prosumidor é incluí-lo digitalmente, mas, conforme aponta Almeida (2007, p. 49), "ser info-incluído não é apenas ser utilizador das tecnologias, mas, antes de tudo, dominar competências básicas que nos permitam navegar na própria vida".

E quais seriam essas competências? Em primeiro lugar saber usar. Transformar comandos e seqüências de cliques (informação) em conhecimento para dele abstrair novas situações e aplicações. A partir daí poder criticar o que se faz, repensando 


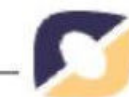

caminhos trilhados e imaginando outros. Por fim, ter autonomia para criar seus próprios caminhos e informações, gerando novos conhecimentos e reciclando antigos.

Partindo desse pressuposto, foi elaborado, no âmbito do Programa de Extensão da Universidade Estadual do Norte Fluminense Darcy Ribeiro intitulado "Utilizando objetos de aprendizagem com professores e alunos de ensino médio" um curso de inclusão digital cujo objetivo era capacitar os alunos a utilizarem as TICs de forma crítica. Para isso, o curso contou com atividades práticas, como passar fotos de uma máquina digital para o PC, fazer um currículo, pesquisar sobre profissões na Internet, entre outros, culminando com a avaliação dos objetos e o conseqüente desenvolvimento da capacidade crítica do aluno.

Assim, a primeira etapa do curso foi dividir os 24 alunos inscritos em 3 grupos de acordo com o nível de inclusão digital dos mesmos, definido a partir das respostas dadas a um questionário de auto-avaliação sobre conhecimentos básicos de microinformática, variando de conhecimentos simples como formatar um texto até mais elaborados como confeccionar uma página. Essa divisão permitiu que o curso fosse adaptado a cada grupo, ou seja, o nível de complexidade das informações e do conteúdo abordado estava de acordo com o nível de inclusão digital de cada um ${ }^{1}$. Estes alunos foram convidados a participar por terem se inscrito em um curso pré-vestibular comunitário oferecido pela UENF.

As atividades relacionadas a familiarização com a informática foram desenvolvidas pelos alunos estando todos no mesmo horário e local, mas com um mediador para cada um dos três grupos organizados. Esta etapa do projeto durou cerca de um mês, com atividades todas as tardes, com duração de 4 horas.

Depois disso os alunos passaram a ter aulas de Química, Física, Biologia e Matemática utilizando objetos de aprendizagem. Ao final, cada um deles avaliou os objetos. A metodologia utilizada e o resultado desta avaliação encontram-se na seção 2. Na seção 3 discutimos a qualidade da avaliação feita pelos alunos sob o ponto de vista dos professores. E na seção 4 encontram-se as considerações finais.

\section{Avaliação dos objetos feita pelos alunos}

A avaliação de um recurso visa, em última instância, determinar se o mesmo é adequado para uso em ambiente educacional e se realmente traz o benefício proposto ao usuário. Para isso, é preciso haver um bom design que tenha como objetivo "reduzir a quantidade de processamento direcionado à interação com o sistema e maximizando o processamento do conhecimento que está sendo ensinado" (GRANDO, KONRATH e TAROUCO, 2003).

Numa avaliação devem ser analisadas características pedagógicas e ergonômicas do software, observando os principais problemas que ocorrem na interação com seus usuários e se este atende aos requisitos relativos à aprendizagem.

\footnotetext{
1 O G1 foi considerado o de nível básico (Conhecimento apenas sobre aplicativos de edição de texto do Sistema Operacional). O G2 foi considerado o de nível intermediário (Conhecimento básico sobre diversas áreas como: Internet, Edição de Texto e Imagens,...). O G3 foi considerado o de nível avançado (Conhecimento aprofundado sobre diversas áreas como: Internet, Edição e texto e Imagens, Uso de outros Programas, Uso correto do Sistema Operacional).
} 


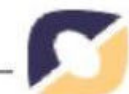

Pensando na necessidade dessa avaliação pelos usuários finais dos objetos (professores e alunos) foram propostas duas metodologias. A primeira tem como foco os professores e contempla quatro dimensões — pedagógica, conteúdo, interface e usabilidade - , subdivididas em 65 perguntas.

Com base nessa metodologia inicial, propusemos aos professores das áreas de domínio contempladas no Programa de Extensão que adaptassem esse questionário para ser utilizado pelos alunos do Ensino Médio. O objetivo era verificar quais critérios poderiam/deveriam ser avaliados pelos alunos e qual a linguagem adequada a esse público alvo.

Após análise feita pelos professores chegou-se a uma metodologia com três dimensões: conteúdo, interface e usabilidade, cada uma delas com critérios a serem analisados, totalizando 25 perguntas com o seguinte gradiente: $\mathrm{CF}$ - concordo fortemente; $\mathrm{C}$ - concordo; N - neutro; D - discordo; DF - discordo fortemente; N/A não se aplica.

A dimensão conteúdo visa avaliar como esse conteúdo foi apresentando, se utilizando várias mídias, se estas auxiliaram na compreensão do conteúdo, se a forma de apresentação estava clara, se o objeto motivou o aluno a utilizá-lo etc.

Quanto ao uso de várias mídias é importante ressaltar que elas permitem que o OA contemple vários estilos de aprendizagem, como afirma Barry (2001). No entanto, ao incluir mídias além do texto deve-se ter o cuidado de utilizá-las como elementos informativos, não como elementos redundantes, que, além de deixarem o OA mais "pesado", podem causam sobrecarga cognitiva nos usuários.

Projetistas de ambientes de aprendizagem utilizam multimídia e interatividade como forma de conseguir uma aprendizagem mais eficaz. Todavia, em alguns ambientes, estes fatores podem resultar em um efeito de distração e causar um impacto negativo no processo de aprendizagem resultando num aumento da carga cognitiva, ou seja, da quantidade de recursos cognitivos alocados a uma tarefa específica. (GRANDO, KONRATH e TAROUCO, 2003).

Na dimensão interface são avaliados aspectos como: legibilidade, adequação da linguagem à faixa etária dos usuários, clareza dos ícones, mensagens e denominações etc. A interface é a parte do OA com a qual o usuário vai interagir, ou seja, é o que o usuário vê do objeto. A interface deve ser o mais amigável possível ou, nas palavras de Lemos (2007), deve haver uma interface zero que possibilite uma simbiose perfeita na interação homem-técnica.

Quanto à legibilidade Nielsen e Loranger (2007) apontam que em vários sites por eles avaliados foram encontrados os seguintes problemas: i) o texto parece muito pequeno e confuso; ii) o texto não é facilmente redimensionável; iii) a cor do texto não fornece um bom contraste sobre o fundo; e iv) o texto está obscurecido pelos elementos do layout.

Outro ponto a ser ressaltado na avaliação da interface é a importância de mensagens de erro, instruções de atividades e botões aparecerem na mesma posição em toda a atividade (NASCIMENTO, 2006). 


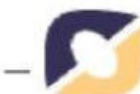

A usabilidade é um termo cada vez mais comum no cotidiano de quem lida com as novas tecnologias. Ela é avaliada por meio da interface, mas a usabilidade não se restringe à interface. Segundo Nielsen e Loranger (2007, p. xvi)

[...] a usabilidade é um atributo de qualidade relacionado à facilidade do uso de algo. Mais especificamente, refere-se à rapidez com que os usuários podem aprender a usar alguma coisa, a eficiência deles ao usá-la, o quanto lembram daquilo, seu grau de propensão a erros e o quanto gostam de utilizá-la.

Dessa forma, esta dimensão tem como objetivo verificar a grau de facilidade de uso do objeto por meio da avaliação de sua navegação, da ajuda oferecida, da prevenção de erros e correta informação caso eles ocorram, entre outros aspectos.

Os alunos avaliaram objetos de química selecionados de dois repositórios: o RIVED (Rede Interativa Virtual de Educação), projeto do Ministério da Educação, e o Labvirt (Laboratório Didático Virtual), que é uma iniciativa da Escola do Futuro da Universidade de São Paulo.

Foram avaliados 18 objetos: 1) Estrutura atômica; 2) A que grupo pertenço?; 3) Cinética dos gases; 4) Usina - lei dos gases; 5) Chuva ácida; 6) Balanceando a equação; 7) A construção; 8) A química do bolo; 9) Porcentagem dos elementos; 10) Radioatividade; 11) Raio X e radioatividade; 12) A tarefa de João; 13) Distribuição de água no planeta; 14) Quem apagou a luz?; 15) Qui-contato; 16) Dipirona; 17) Temperatura alta; e 18) História de um foguete.

Os resultados das avaliações encontram-se na próxima seção.

\section{1 - Resultados das avaliações}

Analisando os gráficos, verificou-se que o maior índice de "concordo" foi no aspecto interface, sendo o aspecto conteúdo também bem avaliado, como pode ser observado no Gráfico 1.

\section{Gráfico 1 - Objetos de Aprendizagem de Química}

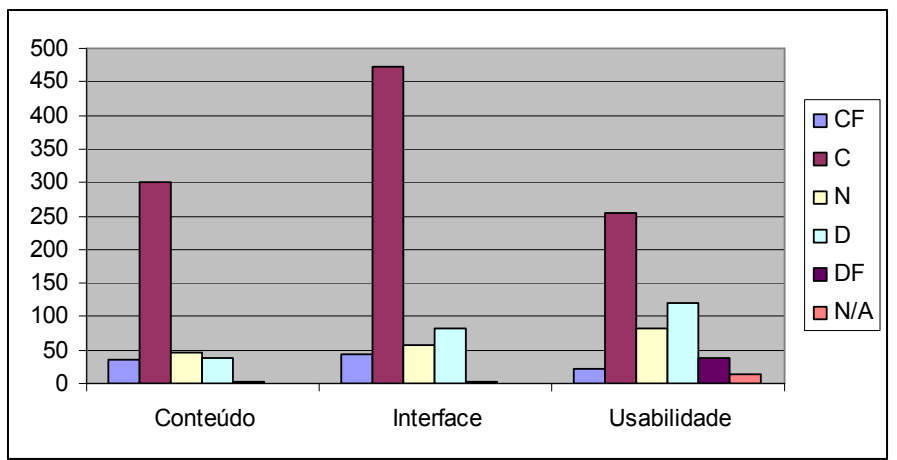

A avaliação da interface indica que a comunicação do objeto com o aluno está adequada, uma vez que é na interface que se dá a interação entre software e usuário. No Gráfico 2 vemos como este item foi bem avaliado nos objetos de Biologia.

\section{Gráfico 2 - Objetos de aprendizagem de Biologia}




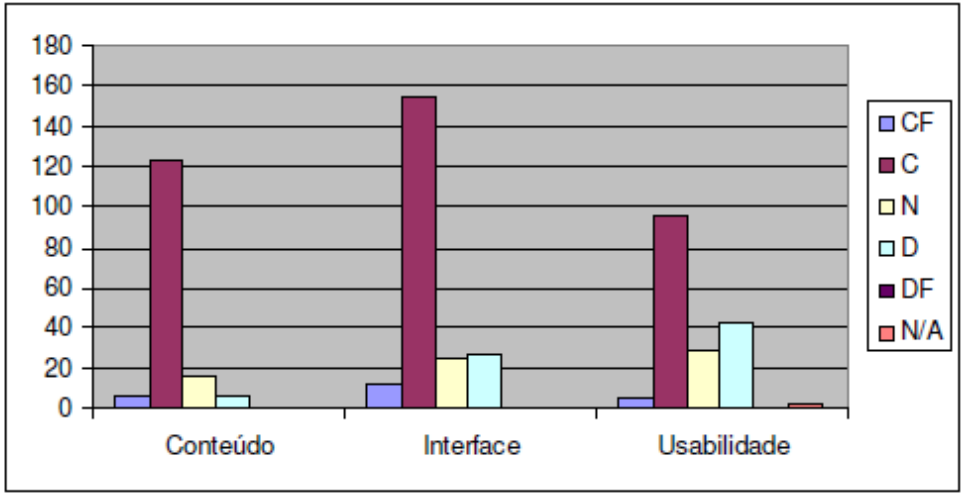

Os principais problemas encontram-se na usabilidade, como mostra bem o Gráfico 3. Um aspecto apontado por alguns professores foi a dificuldade, em alguns objetos, de se voltar à tela anterior. Essa falha prejudica uma das três principais questões feitas pelo usuário ao navegar por um site ou recurso tecnológico: Onde posso ir?. ${ }^{2}$ Além de limitar a navegação do usuário, impede que este responda a uma segunda questão: onde estive?, ou seja, caso não se lembre de onde veio ou deseje voltar para recuperar a informação, a dificuldade e, em alguns casos, a impossibilidade de voltar, causam confusão.

Gráfico 3 - Objetos de Aprendizagem de Química

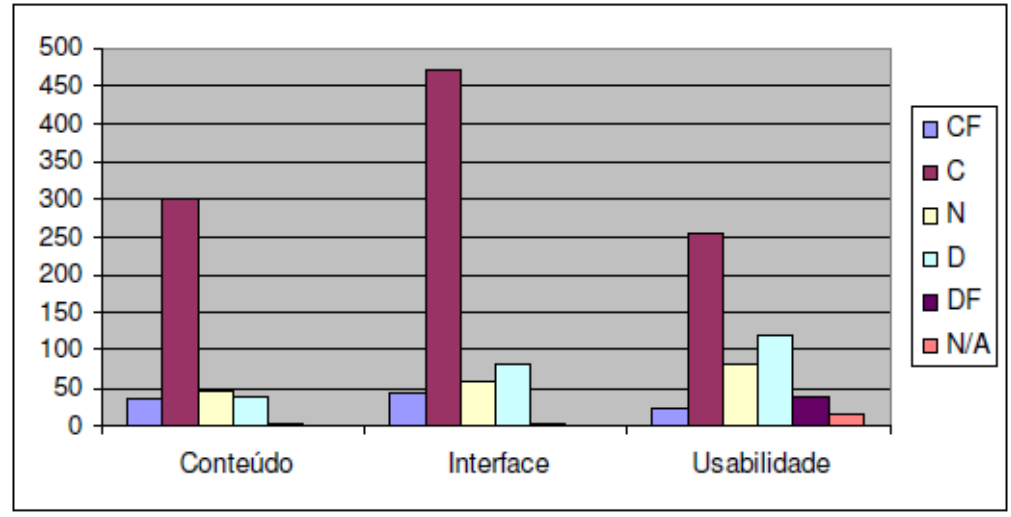

Também é importante ressaltar o número significativo de respostas "neutro" que, no caso da matemática (Gráfico 4), foi a segunda opção mais marcada. Esse resultado pode ter como fonte dois fatores: 1) inadequação do questionário ao público-alvo; e/ou 2) falta de conhecimento necessário dos alunos para responderem às questões propostas.

\section{Gráfico 4 - Objetos de Aprendizagem de Matemática}

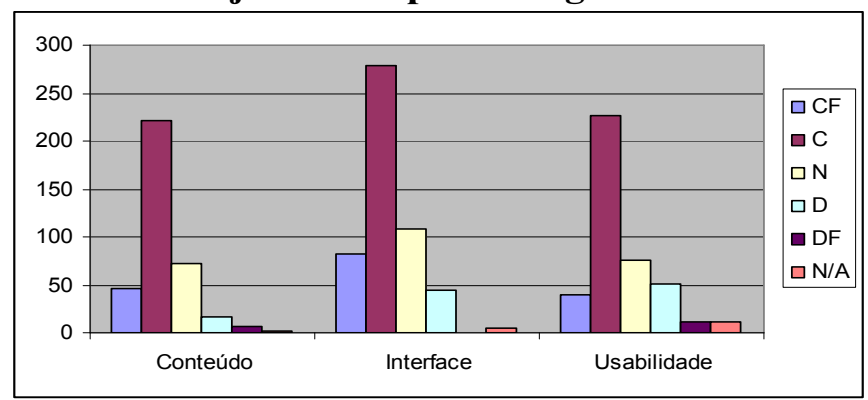

\footnotetext{
${ }^{2}$ As outras duas são: Onde estou? Onde estive?
} 


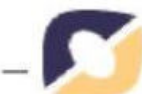

Além da análise dos resultados obtidos com a avaliação dos alunos, os professores fizeram um relatório sobre o momento da avaliação. Os resultados desses relatórios encontram-se na próxima seção.

\section{O resultado das avaliações sob o ponto de vista dos professores}

Com base na avaliação feita pelos alunos e na percepção em sala durante a avaliação dos objetos, os professores de cada área fizeram uma análise da qualidade, veracidade e fidedignidade da resposta dos alunos. Ao todo, estiveram envolvidos no processo três professores de Física, um de Química, um de Matemática e um de Biologia, além de um licenciando de cada uma dessas áreas.

A equipe de matemática aponta:

Analisando os questionários respondidos pelos alunos, podemos perceber que muitas vezes eles não têm noção do que estão respondendo, isto é, a impressão que temos é que ou eles ficam desmotivados e respondem de qualquer jeito ou não conseguem interpretar as perguntas corretamente.

Em relação à motivação, um ponto a ser salientado foi o momento da avaliação, geralmente no fím da aula. Os motivos podem ser o cansaço (o curso era de $13 \mathrm{~h}$ às $17 \mathrm{~h}$ ), o tempo destinado ao preenchimento do questionário, a pressa em ir embora ou a pouca importância dada à avaliação pelos alunos. Esse aspecto foi apontado por um dos professores de Física:

O questionário de avaliação dos objetos de aprendizagem [...] foi preenchido, de certa forma, sem muito interesse, visto que os comentários em relação ao mesmo não costumavam ser muito amistosos e o tempo destinado ao preenchimento (que era de 15 min, tempo considerado satisfatório, devido ao número e grau de informações exigidas pelo questionário, que deveria ser associado a cada objeto utilizado) não foi bem aproveitado.

A questão do mau aproveitamento comentado no parágrafo anterior foi devido à pressa que os alunos tinham em responder o questionário, como se quisessem livrar-se de uma obrigação que consideravam desnecessária e sem utilidade, embora tentássemos explicar sua importância para possível melhoramento do material utilizado além de construir bases de forma a fundamentar sua utilização para uma melhor aprendizagem dos conteúdos em questão.

Quanto à questão de não conseguirem interpretar as perguntas, uma possível causa pode ser o fato destas não serem ligadas a uma tarefa em si, tornando-se assim independentes do contexto de aplicação. Dessa forma, o aluno, ao responder, não consegue se lembrar de um momento específico no objeto em que tal aspecto aparecia e acaba "chutando" a resposta. Outro motivo pode ser o tamanho do questionário, considerado longo por alguns professores, como um de Química:

Um outro fator, além do momento de aplicação, foi o tamanho do questionário. Se fosse um questionário mais estimulante com uma menor quantidade de questões, os alunos não responderiam forçosamente ao questionário, eles se dedicariam mais nas respostas e os resultados não seriam corrompidos nem invalidados. 
[...] a própria linguagem do questionário que, embora adaptado pelos próprios professores, ainda pode ser melhorado.

Ainda um terceiro ponto foi o nível de familiaridade com a linguagem do questionário, ressaltado por um dos professores de Física:

Conhecendo o perfil dos alunos, e sabendo o nível de conhecimentos prévios, deve-se levar em consideração que termos como: mídias, cursor, ícones, menus, interface, quando utilizadas em conjunto, pode ser que o aluno saiba identificar alguns e outros não. Mesmo tendo um curso de inclusão digital, que ocorreu anteriormente, alguns alunos mostraram não entender alguns destes termos.

A observação quanto à familiaridade dos alunos com os termos ligados à Web, apesar do curso de inclusão digital, nos mostra um aspecto importante quando falamos de inclusão digital: esta não se dá pela disponibilização de máquinas, também não se dá em um curto espaço de tempo. Tal qual uma criança recém alfabetizada, que demora a reconhecer algumas palavras, não conhece o significado de outras e comete erros ortográficos, embora saiba ler e escrever, o aluno só vai estar "alfabetizado" digitalmente após um tempo de convivência intensa com as novas tecnologias. Enfatizamos o intensa porque, mais uma vez fazendo um paralelo com a alfabetização escolar, aqueles alunos que não lêem e escrevem freqüentemente acabam tendo uma habilidade menor com a língua do que aqueles que o fazem com mais freqüência. $\mathrm{O}$ mesmo se dá com o uso das novas tecnologias.

No relatório apresentado pela equipe de Biologia fica claro o problema da fidedignidade das respostas:

A uma primeira vista os OAs parecem ter sido avaliados de forma positiva. Contudo, é preocupante que na avaliação do Módulo 73, no item USABILIDADE, na questão 8, referente a "O OA oferece a opção de tirar o som, caso necessário", 3 em 6 estudantes tenham optado por CONCORDAR com a afirmativa. O módulo 73 NÃO usa recursos sonoros e neste caso o correto seria optar por N/A (NÃO SE APLICA) ou mesmo N (NEUTRO).

Esta parece ser a conseqüência dos problemas anteriormente levantados e o sinal do ponto crucial a ser discutido: apesar da importância de ser testar os recursos com os usuários finais, como garantir que sua avaliação será de qualidade?

Claro está que problemas na aplicação do questionário ou do próprio questionário levam a respostas imprecisas e até mesmo incorretas, mas, será que mesmo com um questionário menor, com linguagem mais acessível e uma metodologia de aplicação mais adequada o aluno terá consciência da importância de seu papel como ator crítico? Como garantir que o aluno, tão acostumado a ter tudo previamente selecionado e avaliado pela sua escola/professor, saia do papel de consumidor e esteja preparado para exercer papel de prosumidor, conforme proposto por Almeida (2007), ou até mesmo produtor de conteúdo?

\section{Considerações Finais}




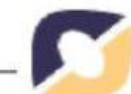

Nessa primeira etapa de avaliação dos OAs pode-se perceber que o questionário ainda não está em sua versão final, precisando de ajustes em sua linguagem e extensão.

Como estudos futuros, deve-se repensar a metodologia de avaliação: a possibilidade de incluir perguntas abertas ou mesmo avaliar por meio de tarefas solicitadas aos usuários e não perguntas gerais pode ser mais adequado ao usuário final dos objetos.

Um outro ponto que pode ser verificado é a necessidade de se rever a usabilidade dos objetos. Embora tenha havido problemas no processo de avaliação, o fato de, em todas as áreas, a dimensão usabilidade ser a que apresentou menor satisfação por parte do usuário é significativo.

Uma outra hipótese que pode ser comprovada e que vem ao encontro do que Nielsen e Loranger (2007) apontam, é a dificuldade de se avaliar recursos digitais com usuários inexperientes no uso das novas tecnologias. Muitas vezes, a dificuldade apresentada por eles não é do recurso em si, mas no uso do computador. Assim é que as avaliações feitas por alunos do grupo 3 parecem mais confiáveis, por exemplo, tendo-se menos respostas incoerentes neste grupo do que nos demais.

Não estamos aqui afirmando que somente usuários experientes devam avaliar, mas reafirmar a importância da inclusão digital para que o usuário/avaliador tenha condições mínimas de avaliar.

Nesse sentido, foi fundamental o curso de inclusão oferecido anteriormente. No entanto, pode-se comprovar, conforme já apontado neste artigo, a necessidade de uma vivência maior dos alunos com a tecnologia. Em outras palavras, não basta ao aluno saber mexer no mouse ou dar um clique duplo, é preciso que as TICs façam parte do seu dia-a-dia. Este talvez seja o grande desafio dos projetos de inclusão digital: após a imersão inicial dos alunos, a exposição dos mesmos a tecnologia não necessariamente é assegurada. E não estando assegurada, muitos esforços podem se perder. Para os alunos participantes do curso o desafio foi maior, tendo em vista o fato de serem oriundos de classes econômicas não muito favorecidas, o que dificulta o acesso à tecnologia.

Dessa forma, a avaliação dos objetos pelos alunos, para ser de qualidade, depende de dois eixos: 1) o instrumento de avaliação adequado ao público-alvo e sua correta aplicação; e 2) a capacitação dos avaliadores quanto ao uso das TICs.

Assim, de nada vale o desenvolvimento de métricas e instrumentos de avaliação se o aluno não estiver preparado para exercer seu papel de cidadão, com um olhar crítico sobre o que lhe é oferecido nessa sociedade do conhecimento. Saber selecionar e avaliar parece-nos condição necessária, mas não suficiente para participar ativamente desta sociedade, saindo do papel de consumidor passivo para o de prosumidor.

\section{Referências}

ALMEIDA, Reginaldo Rodrigues de. O mito da infocracia. Senatus: cadernos da Secretaria de Informação e Documentação / Senado Federal, Secretaria de Informação e Documentação. - vol. 5, n. 1 (mar. 2007). Brasília: Senado Federal, Secretaria Especial de Editoração e Publicações, 2001-. Pp. 46-50. Disponível em: < www.senado.gov.br/sf/publicacoes/revistaSenatus/pdf/Senatus_Vol5.pdf $\quad>$ Acesso em: 20 out. 2007. 


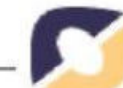

AVELLAR, Rogério; RAPKIEWICZ, Clevi E.; CANELA, Maria Cristina; SANTOS, Angélica Freitas dos. Utilizando mapa conceitual e mapa navegacional no apoio ao processo de desenvolvimento de objetos de aprendizagem. IX Ciclo de Palestras Novas Tecnologias na Educação. UFRGS, 16 a 18 julho.

BARRY, Lisa. "News from online: criteria for an 'outstanding' high school chemistry web site". Journal of Chemical Education. vol. 78, n. 2 fev., 2001. Disponível em: $<$ http://www.JChemEd.chem.wisc.edu.> Acesso em: 17 jul. 2005.

GRANDO, Anita; KONRATH, Mary Lúcia; TAROUCO, Liane. Alfabetização visual para a produção de objetos educacionais. CINTED, v.1, n. 2, set. 2003. Disponível em: $<$ www.cinted.ufrgs.br/renote/set2003/artigos/artigo_anita.pdf $>$. Acesso em: 20 out. 2007.

LEMOS, André. Anjos interativos e retribalização do mundo. Sobre interatividade e interafaces digitais. Disponível em: <www.facom.ufba.br/ciberpesquisa/lemos/ interativo.pdf $>$ Acesso em: 27 out. 2007.

NASCIMENTO, Anna Christina de Azevedo. Princípios de design na elaboração de material multimídia para a Web. Disponível em: <www.rived.mec.gov.br/artigos/multimidia.pdf $>$. Acesso em: 20 out. 2007.

NIELSEN, Jakob; LORANGER, Hoa. Usabilidade na Web: projetando websites com qualidade. Rio de Janeiro: Elsevier, 2007. 